\title{
PENCARIAN AKAR-AKAR PERSAMAAN NONLINIER SATU VARIABEL DENGAN METODE ITERASI BARU HASIL DARI EKSPANSI TAYLOR
}

\author{
SANDI WANDA HARLAN, NARWEN, EFENDI \\ Program Studi Matematika, \\ Fakultas Matematika dan Ilmu Pengetahuan Alam, Universitas Andalas, \\ Kampus UNAND Limau Manis Padang, Indonesia. \\ sandiwandaharlan@gmail.com
}

\begin{abstract}
Abstrak. Makalah ini membahas tentang metode iterasi baru untuk menyelesaikan persamaan nonlinier satu variabel, yang telah dikaji oleh Eskandari [1]. Metode iterasi tersebut diperoleh dari ekspansi deret Taylor orde tiga kemudian diubah menjadi persamaan kuadrat. Metode iterasi baru merupakan suatu pencarian akar persamaan nonlinier dengan menggunakan satu tebakan awal. Kemudian dari tebakan awal tersebut dilakukan proses iterasi untuk mendapatkan akar selanjutnya. Makalah ini juga memuat beberapa contoh kasus yang menunjukkan bahwa metode iterasi baru lebih cepat konvergen daripada metode Newton-Rhapson.

Kata Kunci: Metode Iterasi Baru, Persamaan Nonlinier, Deret Taylor
\end{abstract}

\section{Pendahuluan}

Salah satu masalah yang terjadi pada bidang ilmiah adalah masalah menemukan akar-akar dari fungsi $f(x)=0$. Apabila $f(x)$ adalah linier, maka akar eksaknya dapat ditemukan dengan metode analitik. Akan tetapi apabila persamaannya melibatkan persamaan nonlinier, maka metode analitik tidak dapat digunakan. Oleh karena itu diperlukan metode numerik. Metode numerik adalah teknik yang digunakan untuk menyelesaikan masalah matematika secara penghampiran atau proses perhitungan yang dilakukan secara berulang-ulang untuk mendapatkan solusi yang mendekati solusi eksak (iterasi) .

Ada beberapa metode iterasi yang dapat digunakan untuk menentukan akar dari persamaan nonlinier, diantaranya adalah metode Newton-Rhapson yang menggunakan satu tebakan awal $x_{0}$ untuk proses aproksimasi penarikan akar. Rumus metode Newton-Rhapson diperoleh dari ekspansi deret Taylor orde dua yaitu,

$$
x_{n}=x_{n-1}-\frac{f\left(x_{n-1}\right)}{f^{\prime}\left(x_{n-1}\right)} .
$$

Eskandari [1] telah menemukan metode iterasi baru hasil ekspansi deret Taylor orde tiga yang diubah menjadi persamaan kuadrat dengan proses iterasi yang lebih cepat dari metode Newton-Rhapson. Metode yang digunakan oleh Eskandari [1] merupakan suatu pencarian akar-akar persamaan nonlinier metode terbuka yang hanya menggunakan satu tebakan awal. Kemudian dari tebakan awal tersebut di- 
lakukan proses iterasi untuk mendapatkan akar selanjutnya. Proses iterasi berhenti apabila galat yang diperoleh lebih kecil dari batas toleransi yang ditetapkan.

\section{Proses Terbentuknya Metode Iterasi Baru}

Proses terbentuknya metode iterasi baru diawali dari ekspansi deret Taylor terpotong. Ekspansi deret Taylor $f\left(x_{k+1}\right)$ pada titik $x_{k}$

$$
\begin{aligned}
f\left(x_{k+1}\right)= & f\left(x_{k}\right)+f^{\prime}\left(x_{k}\right)\left(x_{k+1}-x_{k}\right)+\frac{1}{2} f^{\prime \prime}\left(x_{k}\right)\left(x_{k+1}-x_{k}\right)^{2}, \\
& +\frac{1}{6} f^{\prime \prime \prime}\left(x_{k}\right)\left(x_{k+1}-x_{k}\right)^{3}+O\left[\left(x_{k+1}-x_{k}\right)^{4}\right] .
\end{aligned}
$$

Ekspansi deret Taylor $f^{\prime}\left(x_{k+1}\right)$ pada titik $x_{k}$,

$$
\begin{aligned}
f^{\prime}\left(x_{k+1}\right)= & f^{\prime}\left(x_{k}\right)+f^{\prime \prime}\left(x_{k}\right)\left(x_{k+1}-x_{k}\right)+\frac{1}{2} f^{\prime \prime \prime}\left(x_{k}\right)\left(x_{k+1}-x_{k}\right)^{2}, \\
& +O\left[\left(x_{k+1}-x_{k}\right)^{3}\right]
\end{aligned}
$$

Ekspansi deret Taylor $f^{\prime \prime}\left(x_{k+1}\right)$ pada titik $x_{k}$,

$$
f^{\prime \prime}\left(x_{k+1}\right)=f^{\prime \prime}\left(x_{k}\right)+f^{\prime \prime \prime}\left(x_{k}\right)\left(x_{k+1}-x_{k}\right)+O\left[\left(x_{k+1}-x_{k}\right)^{2}\right] .
$$

Proses substitusi diawali dengan mengalikan kedua ruas persamaan (2.2) dengan $(-\omega)\left(x_{k+1}-x_{k}\right)$, dimana $\omega$ adalah sebuah konstanta sebarang bilangan real dan $\omega \neq 0$, sehingga

$$
\begin{aligned}
-\omega\left(x_{k+1}-x_{k}\right) f^{\prime}\left(x_{k+1}\right)= & -\omega\left(x_{k+1}-x_{k}\right) f^{\prime}\left(x_{k}\right) \\
& -\omega f^{\prime \prime}\left(x_{k}\right)\left(x_{k+1}-x_{k}\right)^{2}, \\
& -\frac{1}{2} \omega f^{\prime \prime \prime}\left(x_{k}\right)\left(x_{k+1}-x_{k}\right)^{3} \\
& +O\left[\left(x_{k+1}-x_{k}\right)^{4}\right] .
\end{aligned}
$$

Kemudian kedua ruas persamaan (2.3) dikalikan dengan $\left(\frac{1}{2} \omega-\frac{1}{6}\right)\left(x_{k+1}-x_{k}\right)^{2}$ sehingga

$$
\begin{aligned}
\left(\frac{1}{2} \omega-\frac{1}{6}\right)\left(x_{k+1}-x_{k}\right)^{2} f^{\prime \prime}\left(x_{k+1}\right)= & \left(\frac{1}{2} \omega-\frac{1}{6}\right)\left(x_{k+1}-x_{k}\right)^{2} f^{\prime \prime}\left(x_{k}\right) \\
& +\left(\frac{1}{2} \omega-\frac{1}{6}\right)\left(x_{k+1}-x_{k}\right)^{3} f^{(3)}\left(x_{k}\right) \\
& +O\left[\left(x_{k+1}-x_{k}\right)^{4}\right] .
\end{aligned}
$$

Bila tiga persamaan (2.1), (2.4) dan (2.6) ditambahkan, maka akan diperoleh hasil,

$$
\begin{aligned}
& f\left(x_{k+1}\right)-\omega\left(x_{k+1}-x_{k}\right) f^{\prime}\left(x_{k+1}\right)+\left(\frac{1}{2} \omega-\frac{1}{6}\right)\left(x_{k+1}-x_{k}\right)^{2} f^{\prime \prime}\left(x_{k+1}\right) \\
= & f\left(x_{k}\right)+\left(x_{k+1}-x_{k}\right) f^{\prime}\left(x_{k}\right)+\frac{1}{2}\left(x_{k+1}-x_{k}\right)^{2} f^{\prime \prime}\left(x_{k}\right) \\
& -\omega\left(x_{k+1}-x_{k}\right) f^{\prime}\left(x_{k}\right)-\omega\left(x_{k+1}-x_{k}\right)^{2} f^{\prime \prime}\left(x_{k}\right) \\
& +\left(\frac{1}{2} \omega-\frac{1}{6}\right)\left(x_{k+1}-x_{k}\right)^{2} f^{\prime \prime}\left(x_{k}\right)+O\left[\left(x_{k+1}-x_{k}\right)^{4}\right] .
\end{aligned}
$$


Karena $O\left[\left(x_{k+1}-x_{k}\right)\right]^{4}$ adalah galat dan dengan mengaproksimasikan $f^{\prime}\left(x_{k+1}\right)$ ke $f^{\prime}\left(x_{k}\right)$ dan $f^{\prime \prime}\left(x_{k+1}\right)$ ke $f^{\prime \prime}\left(x_{k}\right)$, maka persamaan (2.7) menjadi

$$
\begin{aligned}
f\left(x_{k+1}\right)= & f\left(x_{k}\right)+\left(x_{k+1}-x_{k}\right) f^{\prime}\left(x_{k}\right)+\frac{1}{2}\left(x_{k+1}-x_{k}\right)^{2} f^{\prime \prime}\left(x_{k}\right) \\
& -\omega\left(x_{k+1}-x_{k}\right)^{2} f^{\prime \prime}\left(x_{k}\right) .
\end{aligned}
$$

Selanjutnya agar $x_{k+1}$ merupakan akar dari $f\left(x_{k+1}\right)$, maka $f\left(x_{k+1}\right)$ harus bernilai nol, sehingga diperoleh

$$
(1-2 \omega) f^{\prime \prime}\left(x_{k}\right)\left(x_{k+1}-x_{k}\right)^{2}+2 f^{\prime}\left(x_{k}\right)\left(x_{k+1}-x_{k}\right)+2 f\left(x_{k}\right)=0 .
$$

Jika diasumsikan $x_{k+1}-x_{k}=\triangle$ maka persamaan (2.9) menjadi,

$$
A \triangle^{2}+B \triangle+C=0
$$

dimana $A=(1-2 \omega) f^{\prime \prime}\left(x_{k}\right), B=2 f^{\prime}\left(x_{k}\right)$ dan $C=2 f\left(x_{k}\right)$ Nilai $\triangle$ dapat dicari dengan rumus $\mathrm{ABC}$, yaitu

$$
\triangle=\frac{-B \pm \sqrt{B^{2}-4 A C}}{2 A}
$$

Karena $x_{k+1}-x_{k}=\triangle$ maka,

$$
x_{k+1}=x_{k}-\frac{f^{\prime}\left(x_{k}\right) \pm \sqrt{f^{\prime}\left(x_{k}\right)^{2}-2(1-2 \omega) f^{\prime \prime}\left(x_{k}\right) f\left(x_{k}\right)}}{(1-2 \omega) f^{\prime \prime}\left(x_{k}\right)}
$$

Persamaan (2.12) adalah persamaan metode iterasi awal dengan $\omega$ berlaku untuk setiap bilangan real. Karena berlaku untuk setiap bilangan real untuk mempermudah proses iterasi, ambil $\omega=0$. Hal ini dilakukan untuk mempermudah proses penghitungan. Akibatnya diperoleh persamaan akhir dari metode iterasi baru yaitu,

$$
x_{k+1}=x_{k}-\frac{f^{\prime}\left(x_{k}\right) \pm \sqrt{f^{\prime}\left(x_{k}\right)^{2}-2 f^{\prime \prime}\left(x_{k}\right) f\left(x_{k}\right)}}{f^{\prime \prime}\left(x_{k}\right)}
$$

\section{Contoh Kasus}

Metode iterasi tersebut dapat digunakan untuk beberapa contoh kasus persamaan nonlinier sebagai berikut.

Contoh 3.1. Gunakan metode Iterasi untuk mencari akar dari

$$
f(x)=x^{5}-7 x^{2}+11 x-6 .
$$

Untuk mencari akar dari persamaan $f(x)=0$, harus ditentukan $x_{0}$ sebagai tebakan awal dan $\epsilon$ sebagai galat. Misal $x_{0}=1$ dan $\epsilon=10^{-20}$. Hitung turunan pertama dan kedua dari fungsi $f(x)$. Diperoleh $f^{\prime}(x)=5 x^{4}-14 x+11$ dan $f^{\prime \prime}(x)=20 x-14$.

Perbandingan hasil dan proses iterasi pencarian akar persamaan $f(x)=x^{5}$ $7 x^{2}+11 x-6$ metode Newton-Rhapson dan metode iterasi baru dapat dilihat pada Tabel 1 dan 2 .

Contoh 3.2. Gunakan metode Iterasi untuk mencari akar dari

$$
f(x)=23 \ln x-e^{-x} .
$$




\begin{tabular}{|l|l|l|}
\hline$n$ & \multicolumn{1}{|c|}{$x_{n}$} & \multicolumn{1}{|c|}{$f\left(x_{n}\right)$} \\
\hline 0 & 1 & $-1 \mid$ \\
1 & 1.33333333333333333333 & 0.4362139917695473244 \\
2 & 1.2719911727729119486 & -0.0040099766892070202 \\
3 & 1.2726287113045894060 & $4.1936901807 * 10^{-9}$ \\
4 & 1.2726287106387612287 & 0 \\
5 & 1.2726287106387612287 & 0 \\
\hline
\end{tabular}

Gambar 1. Proses iterasi untuk pencarian akar $f(x)=x^{5}-7 x^{2}+11 x-6$ dengan metode iterasi baru

\begin{tabular}{|l|l|l|}
\hline$n$ & \multicolumn{1}{|c|}{$x_{n}$} & \multicolumn{1}{|c|}{$f\left(x_{n}\right)$} \\
\hline 0 & 1 & -1 \\
1 & 1.5000000000000000000 & 2.3437500000000000000 \\
2 & 1.3469387755102040816 & 0.5500421737835161625 \\
3 & 1.2829823523187787166 & 0.0666891177415742415 \\
4 & 1.2728557643068695297 & 0.0014307896731732935 \\
5 & 1.2726288219991140904 & $7.013985679578 \times 10^{-7}$ \\
6 & 1.2726287106387880283 & $1.687966 \times 10^{-13}$ \\
7 & 1.2726287106387612286 & $-4 \times 10^{-19}$ \\
8 & 1.2726287106387612287 & 0 \\
9 & 1.2726287106387612287 & 0 \\
\hline
\end{tabular}

Gambar 2. Proses iterasi untuk pencarian akar $f(x)=x^{5}-7 x^{2}+11 x-6$ dengan metode NewtonRhapson

Untuk mencari akar dari persamaan $f(x)=0$, harus ditentukan $x_{0}$ sebagai tebakan awal dan $\epsilon$ sebagai galat. Misal $x_{0}=1$ dan $\epsilon=10^{-20}$. Hitung turunan pertama dan kedua dari fungsi $f(x)$. Diperoleh $f^{\prime}(x)=\frac{23}{x}+e^{-x}$ dan $f^{\prime \prime}(x)=-\frac{23}{x^{2}}-e^{-x}$.

Perbandingan hasil dan proses iterasi pencarian akar persamaan $f(x)=23 \ln x-$ $e^{-x}$ menggunakan metode Newton-Rhapson dan metode iterasi baru dapat dilihat pada Tabel 3 dan 4 .

\begin{tabular}{|l|l|l|}
\hline$n$ & \multicolumn{1}{|c|}{$x_{n}$} & \multicolumn{1}{|c|}{$f\left(x_{n}\right)$} \\
\hline 0 & 1 & -0.3678794411714423216 \\
1 & 1.0158688639965378214 & 0.00003052083411893938 \\
2 & 1.0158675371664451761 & $-1.621^{*} 10^{-17}$ \\
3 & 1.0158675371664451768 & 0 \\
4 & 1.0158675371664451768 & 0 \\
\hline
\end{tabular}

Gambar 3. Proses iterasi untuk pencarian akar $f(x)=23 \ln x-e^{-x}$ dengan metode iterasi baru 


\begin{tabular}{|l|l|l|}
\hline$n$ & \multicolumn{1}{|c|}{$x_{n}$} & \multicolumn{1}{c|}{$f\left(x_{n}\right)$} \\
\hline 0 & 1 & -0.36787944117144232160 \\
1 & 1.0157429535742675143 & -0.00286595163264867639 \\
2 & 1.0158675295249162223 & $-1.7577683243137 \times 10^{-7}$ \\
3 & 1.0158675371664451481 & $-6.6030 \times 10^{-16}$ \\
4 & 1.0158675371664451768 & 0 \\
5 & 1.0158675371664451768 & 0 \\
\hline
\end{tabular}

Gambar 4. Proses iterasi untuk pencarian akar $f(x)=23 \ln x-e^{-x}$ dengan metode NewtonRhapson

Contoh 3.3. Gunakan metode Iterasi untuk mencari akar dari

$$
f(x)=7 x^{2}-\cos x+\sin x .
$$

Untuk mencari akar dari persamaan $f(x)=0$, harus ditentukan $x_{0}$ sebagai tebakan awal dan $\epsilon$ sebagai galat. Misal $x_{0}=1$ dan $\epsilon=10^{-20}$. Hitung turunan pertama dan kedua dari fungsi $f(x)$. Diperoleh $f^{\prime}(x)=14 x+\cos x+\sin x$ dan $f^{\prime \prime}(x)=$ $14+\cos x-\sin x$.

Perbandingan hasil dan proses iterasi pencarian akar persamaan $f(x)=7 x^{2}-$ $\cos x+\sin x$ dengan menggunakan metode Newton-Rhapson dan metode iterasi baru dapat dilihat pada Tabel 5 dan 6 .

\begin{tabular}{|l|l|l|}
\hline$n$ & \multicolumn{1}{|c|}{$x_{n}$} & \multicolumn{1}{c|}{$f\left(x_{n}\right)$} \\
\hline 0 & 1 & 7.3011686789397567892 \\
1 & 0.31855818289088604472 & 0.0738648427430953626 \\
2 & 0.30543045526153689793 & $4.7539951161955 * 10^{-7}$ \\
3 & 0.30543036930112453937 & 0 \\
$4 \mid$ & 0.30543036930112453937 & 0 \\
\hline
\end{tabular}

Gambar 5. Proses iterasi untuk pencarian akar $f(x)=7 x^{2}-\cos x+\sin x$ dengan metode iterasi baru

\begin{tabular}{|l|l|l|}
\hline$n$ & \multicolumn{1}{|c|}{$x_{n}$} & \multicolumn{1}{|c|}{$f\left(x_{n}\right)$} \\
\hline 0 & 1 & 29.325444263372824082 \\
1 & 0.9707896931068671773 & 6.8577123185255789293 \\
2 & 0.51303012709726914650 & 1.4619576434619237878 \\
3 & 0.34193091668227001076 & 0.21161513987207075213 \\
4 & 0.30703654262319904758 & 0.00890175555232974398 \\
5 & 0.30543377211064249202 & 0.00001881914065752708 \\
6 & 0.30543036931646392813 & $8.483366815 \times 10^{-11}$ \\
7 & 0.30543036930112453937 & 0 \\
8 & 0.30543036930112453937 & 0 \\
\hline
\end{tabular}

Gambar 6. Proses iterasi untuk pencarian akar $f(x)=7 x^{2}-\cos x+\sin x$ dengan metode NewtonRhapson 
98 Sandi Wanda Harlan dkk.

\section{Ucapan Terima kasih}

Penulis mengucapkan terima kasih kepada Ibu Lyra Yulianti, Bapak Mahdhivan Syafwan dan Ibu Susila Bahri yang telah memberikan masukan dan saran dalam penyempurnaan penulisan artikel ini.

\section{Daftar Pustaka}

[1] Eskandari, H. (2008). A New Numerical Solving Method for Equations of One Variable. Proceeding of the World Academy of Science: Engineering and Technology 46: 196 - 199

[2] Ayres, Frank. dan P. A. Schmidt. 2004. Theory and Problems of Collage Mathematics, $2^{e d}$. McGraw Hill, Inc. Boston.

[3] Chapra S.C and R. P. Canale. 2002. Numerical Method For Engineer. McGraw Hill, Inc. Boston.

[4] Heirstein, L. N. 2000. Topics in Algebra. John Wiley and Sons, Inc. Chicago.

[5] Munir, Rinaldi. 2003. Metode Numerik. Informatika, Bandung.

[6] Purcell, E.J Dale Verberg dan Steven E. R. 2003. Kalkulus Edisi ke-8. Erlangga, Jakarta.

[7] Abidin, Zaenal. 2012. Bahan Ajar Metode Numerik, Fakultas Ilmu Pengetahuan Alam. UNS Semarang.

[8] Bartle, Robert G. 2000. Introduction to Real Analysis. John Wiley and Sons, Inc. New York.

[9] Mayr, Richard. 2000. Discrete Mathematics. University of Edinburgh. London. 